\title{
The Dietary Approaches to Stop Hypertension (DASH) diet, Western diet, and risk of gout in men: prospective cohort study
}

\author{
Sharan K Rai, ${ }^{1,2,3}$ Teresa T Fung, ${ }^{4,5}$ Na Lu, ${ }^{1,2}$ Sarah F Keller, ${ }^{1}$ Gary C Curhan, ${ }^{2,6}$ Hyon K Choi1,2,3
}

'Division of Rheumatology, Allergy and Immunology,

Massachusetts General

Hospital, Harvard Medical

School, Boston, MA, 02114, USA

${ }^{2}$ Channing Division of Network

Medicine, Department of

Medicine, Brigham and Women's

Hospital, Harvard Medical

School, Boston, MA, USA

${ }^{3}$ Arthritis Research Canada,

Richmond, BC, Canada

${ }^{4}$ Department of Nutrition,

Simmons College, Boston,

MA, USA

${ }^{5}$ Department of Nutrition, Harvard TH Chan School of

Public Health, Boston, MA, USA

${ }^{6}$ Division of Renal (Kidney)

Medicine, Department of

Medicine, Brigham and Women's

Hospital, Harvard Medical

School, Boston, MA, USA

Correspondence to: $\mathrm{HK}$ Choi

hchoi@partners.org

Cite this as: BMJ 2017;357:j1794 http://dx.doi.org/10.1136/bmj.j1794

Accepted: 3 April 2017

\author{
ABSTRACT \\ OBJECTIVE \\ To prospectively examine the relation between the \\ Dietary Approaches to Stop Hypertension (DASH) and \\ Western diets and risk of gout (ie, the clinical endpoint \\ of hyperuricemia) in men.
}

DESIGN

Prospective cohort study.

SETTING

The Health Professionals Follow-up Study. PARTICIPANTS

44444 men with no history of gout at baseline. Using validated food frequency questionnaires, each participant was assigned a DASH dietary pattern score (based on high intake of fruits, vegetables, nuts and legumes, low fat dairy products, and whole grains, and low intake of sodium, sweetened beverages, and red and processed meats) and a Western dietary pattern score (based on high intake of red and processed meats, French fries, refined grains, sweets, and desserts).

\section{MAIN OUTCOME MEASURE}

Risk of incident gout meeting the preliminary American College of Rheumatology survey criteria for gout, adjusting for potential confounders, including age, body mass index, hypertension, diuretic use, and alcohol intake.

\section{RESULTS}

During 26 years of follow-up, 1731 confirmed cases of incident gout were documented. A higher DASH dietary pattern score was associated with a lower risk for gout (adjusted relative risk for extreme fifths 0.68, 95\% confidence interval 0.57 to 0.80 , P value for trend $<0.001)$. In contrast, a higher Western dietary pattern

\section{WHAT IS ALREADY KNOWN ON THIS TOPIC}

The Dietary Approaches to Stop Hypertension (DASH) diet (based on high intake of fruits, vegetables, nuts and legumes, low fat dairy products, and whole grains, and low intake of sodium, sweetened beverages, and red and processed meats) reduces blood pressure and is also recommended to prevent cardiovascular disease

A recent analysis of a DASH randomized trial found that the DASH diet also lowers levels of serum uric acid among patients with hyperuricemia; however,

corresponding data for the risk of gout are not available

In contrast, the Western diet (based on high intake of red and processed meats, French fries, refined grains, sweets, and desserts) contains many individual foods that have previously been established to increase levels of serum uric acid and the risk of gout

\section{WHAT THIS STUDY ADDS}

The DASH diet is associated with a lower risk of gout, whereas the Western diet is associated with a higher risk of gout

The DASH diet may provide an attractive preventive dietary approach for the risk of gout

score was associated with an increased risk for gout (1.42, 1.16 to $1.74, \mathrm{P}=0.005)$.

\section{CONCLUSION}

The DASH diet is associated with a lower risk of gout, suggesting that its effect of lowering uric acid levels in individuals with hyperuricemia translates to a lower risk of gout. Conversely, the Western diet is associated with a higher risk of gout. The DASH diet may provide an attractive preventive dietary approach for men at risk of gout.

\section{Introduction}

Gout is the most common inflammatory arthritis and is caused by hyperuricemia. The prevalence of gout has increased over several decades among adults in the UK and USA to $3.2 \%$ and 3.9\%, respectively. ${ }^{12}$ This disease burden is further complicated by a high level of cardiovascular metabolic comorbidities ${ }^{3}$ (eg, hypertension in $74 \% \%^{3}$ of patients and metabolic syndrome in $63 \%{ }^{4}$ ) and their sequelae (eg, an increased future risk of myocardial infarction ${ }^{5}$ and premature death ${ }^{6}$ ). The conventional approach of a diet low in purine for gout care offers limited efficacy, palatability, and sustainability. This low protein diet promotes increased consumption of refined carbohydrates (including fructose) and unhealthy fats (including trans fats) that can actually worsen cardiovascular metabolic comorbidities by furthering insulin resistance and increasing levels of plasma glucose, triglycerides, and low density lipoprotein cholesterol. ${ }^{78}$ Therefore, there is a key unmet need for an effective dietary strategy to address both the morbidity burden of gout and its associated cardiovascular metabolic comorbidities.

There are proved effective dietary approaches for cardiovascular metabolic conditions that could also lower serum uric acid levels. For example, the Dietary Approaches to Stop Hypertension (DASH) diet substantially reduces blood pressure and is recommended for preventing cardiovascular disease. ${ }^{9}$ The DASH diet emphasizes intake of fruits, vegetables, low fat dairy foods, and reduced saturated and total fat. Furthermore, a recent ancillary analysis of an original DASH randomized trial found that the DASH diet lowers serum uric acid levels substantially among people with hyperuricemia compared with a typical American diet. ${ }^{10}$ Thus, the DASH diet may be particularly useful in gout care by reducing both serum uric acid levels and cardiovascular disease risk. This is especially relevant to patients with hypertension, a common comorbidity of gout ${ }^{3}$; however, corresponding data for the risk of gout are not available. Conversely, the Western diet (reflecting higher intake of red and processed meats, beverages sweetened with sugar, sweets, desserts, French fries, and refined grains) contains many foods 
that have previously been established to increase serum uric acid levels and the risk of gout, which may explain the increasing prevalence of gout in Western countries. $^{21112}$ However, no direct data linking the Western diet with the risk of gout are available.

Although individual nutrients and foods that are associated with hyperuricemia and gout risk have been identified, ${ }^{13-25}$ in reality they are consumed in combination and therefore their joint associations can be best investigated by considering the entire eating pattern. ${ }^{26}$ Furthermore, the analysis of food consumption in the form of dietary patterns (eg, the DASH and Western diets) offers a comprehensive approach to disease prevention and treatment by addressing the collective health benefit of the whole diet and enhancing the applicability and sustainability in practice. Various dietary studies have indicated that changes in dietary patterns (including the DASH diet) can decrease major clinical endpoints such as blood pressure, body mass index, and cardiovascular risk factors as well as disease complications. ${ }^{27-32}$ However, data on the relation between dietary patterns and the risk of gout are scarce.

Thus, we evaluated the relation between the DASH and Western diets and the risk of gout (ie, the clinical endpoint of hyperuricemia) in a large prospective cohort, and we hypothesized opposing associations with these two diets.

\section{Methods}

\section{Study population}

The Health Professionals Follow-up Study (HPFS) is an ongoing longitudinal study that was established in 1986 when 51529 male dentists, optometrists, osteopaths, pharmacists, podiatrists, and veterinarians returned a mailed questionnaire assessing diet, medical history, and medication use. The men are predominantly white (91\%) and were aged 40 to 75 in 1986. Eligible person time follow-up for the HPFS has exceeded $90 \%$ at each two year assessment cycle. We limited our analysis to men who provided complete information on dietary patterns and excluded those with a history of gout before 1986. A total of 44444 men were included in this analysis.

\section{Assessment of dietary patterns}

Beginning in 1986, dietary intake was assessed every four years using a validated food frequency questionnaire that inquired about the average intake of individual foods and beverages during the previous year. ${ }^{131633-35}$ The current version of the questionnaire used in the HPFS includes more than 130 individual foods each with nine frequency choices, plus supplemental vitamins, minerals, as well as an open ended section for foods that are not specified on the questionnaire. The reproducibility and validity of the food frequency questionnaire has been documented in the HPFS as well as in the Nurses' Health Study. ${ }^{333436}$

To represent the Dietary Approaches to Stop Hypertension (DASH) diet for all participants, we used a previously derived DASH dietary pattern score based on individual dietary components from the food frequency questionnaire that are emphasized or minimized in the DASH diet, ${ }^{3738}$ focusing a priori on its eight key food or nutrient group components: high intake of fruits, vegetables, nuts and legumes, low fat dairy products, and whole grains, and low intake of sodium, sweetened beverages, and red and processed meats. ${ }^{39}$ The original DASH diet also limits saturated fat intake, which is reflected in part by a low emphasis on red and processed meats in this DASH score. ${ }^{37}$ For each of the components, all participants were classified into fifths according to their intake ranking. The fifth rankings were assigned as the component score for each of the five healthy food group items (fruits, vegetables, nuts and legumes, low fat dairy products, and whole grains). For example, the first fifth is assigned 1 point and the fifth fifth is assigned 5 points. In contrast, low intake is desired for sodium, sweetened beverages, and red and processed meats. Therefore, the lowest fifth for each of these three items was given a score of 5 points and the highest fifth was given 1 point. We then summed the component scores to obtain an overall DASH score for each participant, ranging from 8 to 40 . This DASH score has been successfully used in our prior cohort studies for the risk of cardiovascular disease and kidney stones. ${ }^{37} 38$

To represent the dietary patterns of many modern Western countries, we used a Western dietary pattern previously identified in this cohort, which was characterized by higher intakes of red and processed meats, sugar sweetened beverages, sweets, desserts, French fries, and refined grains. A higher Western dietary pattern score has previously been shown to be associated with an increased risk for type 2 diabetes, coronary heart disease, and colon cancer in our cohorts. ${ }^{2640-43} \mathrm{As}$ previously detailed, the Western dietary pattern score was previously derived in this cohort by applying the principal components program for factor analysis, which aggregates correlated foods to exposure data obtained from the food frequency questionnaire. ${ }^{2644}$ Each participant was assigned a Western pattern score by summing the standardized intake of each food group, weighted by the factor loadings of the foods. ${ }^{45}$

\section{Assessment of non-dietary factors}

The participants provided information on weight, regular use of medications (including thiazides and loop diuretics), and medical conditions (including hypertension) at baseline, and every two years thereafter. ${ }^{35}$ Body mass index was calculated using the most recently updated weight. Self reporting of these data have been found to be reliable in validation studies, and previous studies have shown the lifestyle information provided by participants is able to predict the risk of relevant future diseases, including gout. ${ }^{13161923}$

\section{Ascertainment of incident gout}

We ascertained incident cases of gout using the American College of Rheumatology survey criteria for gout, as previously described. ${ }^{13163546}$ Participants indicated whether they had received a diagnosis of gout from a physician on each biennial questionnaire. We mailed a 
supplementary questionnaire to those participants who had reported incident gout diagnosed from 1986 onwards to confirm the report and to ascertain the preliminary American College of Rheumatology criteria for gout. ${ }^{13163546}$ The primary endpoint in this study was incident gout that met six or more of the 11 criteria for gout (more than one attack of acute arthritis, maximum inflammation developed within one day, oligoarthritis attack, redness observed over joints, painful or swollen first metatarsophalangeal joint, unilateral first metatarsophalangeal joint attack, unilateral tarsal joint attack, tophus, hyperuricemia, asymmetric swelling within a joint (or on radiography), and complete termination of an attack). ${ }^{13163546}$ The overall response rate for the supplementary gout questionnaire was $80 \%{ }^{13}$ To confirm the validity of the gout criteria in our cohort two rheumatologists, who were board certified, reviewed the medical records from a sample of 50 of the men who had reported having gout. The concordance rate between the criteria and the medical record review was $94 \%$.

\section{Statistical analysis}

We computed person time in years for each participant from the return date of the 1986 questionnaire to the date of gout diagnosis, death, or the end of the study period (2012), whichever came first. We excluded participants from subsequent follow-up who died or reported having gout on previous questionnaires.

To best represent the average dietary intake by individual participants over the long term, we used the cumulative average intake based on the dietary information from baseline to the latest point of follow-up as a time varying variable. ${ }^{1316354748}$ For example, the incidence of gout from 1986 through 1990 in the HPFS was computed using the intake data from the 1986 questionnaire, and the incidence from 1990 through 1994 was computed using the average of intakes reported on the 1986 and 1990 questionnaires.

We used Cox proportional hazards modeling (PROC PHREG) to estimate the relative risk for incident gout in all multivariable analyses (Version 9.3, SAS Institute, Cary, NC). For these analyses, we categorized the DASH and Western dietary pattern scores into fifths. Multivariable models were adjusted for several variables in a time varying manner: age (continuous), total energy intake (continuous), body mass index ( $<21,21.0-22.9$, 23.0-24.9, 25.0-29.9, 30.0-34.9, and $\geq 35 \mathrm{~kg} / \mathrm{m}^{2}$ ), use of diuretics (yes or no), history of hypertension (yes or no), history of renal failure (yes or no), alcohol intake (0, 0.14.9, 5.0-9.9, 10.0-14.9, 15.0-29.9, 30.0-49.9, and $\geq 50.0 \mathrm{~g} /$ day), and coffee intake ( $0,<1,1-3$, and $\geq 4$ cups/day). ${ }^{131635}$ Trends in gout risk across categories of dietary pattern scores were assessed in Cox proportional hazards models by using the median values of intake for each category to minimize the influence of outliers. We conducted analyses stratified by body mass index $(<25 \mathrm{~kg} /$ $\mathrm{m}^{2}$ or $\geq 25 \mathrm{~kg} / \mathrm{m}^{2}$ ), alcohol use (yes or no), and hypertension (yes or no) to assess potential effect modification. We tested the significance of the interaction using the likelihood ratio test by comparing a model with the main effects of each intake and the stratifying variable and the interaction term with a reduced model with only the main effects. For all relative risks, we calculated 95\% confidence intervals. All $\mathrm{P}$ values are two sided.

\section{Patient involvement}

Patient input (from the Arthritis Patient Advisory Board, an established arthritis research patient group) was sought in the development of the research question investigated in this report, and a recent survey conducted by the Gout and Uric Acid Education Society ${ }^{49}$ additionally found a preference for non-pharmacologic options among many patients with gout. Moreover, in collaboration with the same patient group, we have developed a dissemination plan that includes a presentation of our findings at an annual public forum as well as the production of a short educational video, both of which include the contents of this report.

\section{Results}

\section{Baseline characteristics}

Over 26 years of follow-up, we documented 1731 newly diagnosed gout cases meeting the American College of Rheumatology criteria (1500 (86.7\%) with podagra, 1226 (70.8\%) with hyperuricemia, 605 (35.0\%) with tarsal joint involvement, and 167 (9.6\%) with tophi). Table 1 shows the characteristics of the cohort according to fifths of the Dietary Approaches to Stop Hypertension (DASH) and Western dietary pattern scores at baseline. Men in the highest fifth of DASH dietary pattern score tended to be older and had a lower body mass index compared with participants in the lowest fifth. Men in the highest fifth of DASH dietary pattern score also had lower intakes of alcohol and coffee than participants in the lowest fifth. Comparatively, men in the highest fifth of Western pattern score tended to be younger, had a higher body mass index, and had higher intakes of alcohol and coffee.

\section{DASH dietary pattern and incident gout}

Table 2 and figure 1 show that a higher DASH dietary pattern score was associated with a lower risk of incident gout in both age adjusted and multivariable regression models. After adjusting for age, total energy intake, body mass index, diuretic use, history of hypertension, history of renal failure, alcohol intake, and coffee intake, the relative risk for men in the highest fifth compared with the lowest fifth of DASH dietary pattern score was 0.68 (95\% confidence interval 0.57 to $0.80, \mathrm{P}$ value for trend $<0.001)$.

\section{Western dietary pattern and incident gout}

Table 2 and figure 2 show that a higher Western dietary pattern score was associated with a higher risk of incident gout in both age adjusted and multivariable regression models. After adjusting for age, total energy intake, body mass index, diuretic use, history of hypertension, history of renal failure, alcohol intake, and coffee intake, the relative risk for men in the highest fifth compared with the lowest fifth of Western dietary pattern 

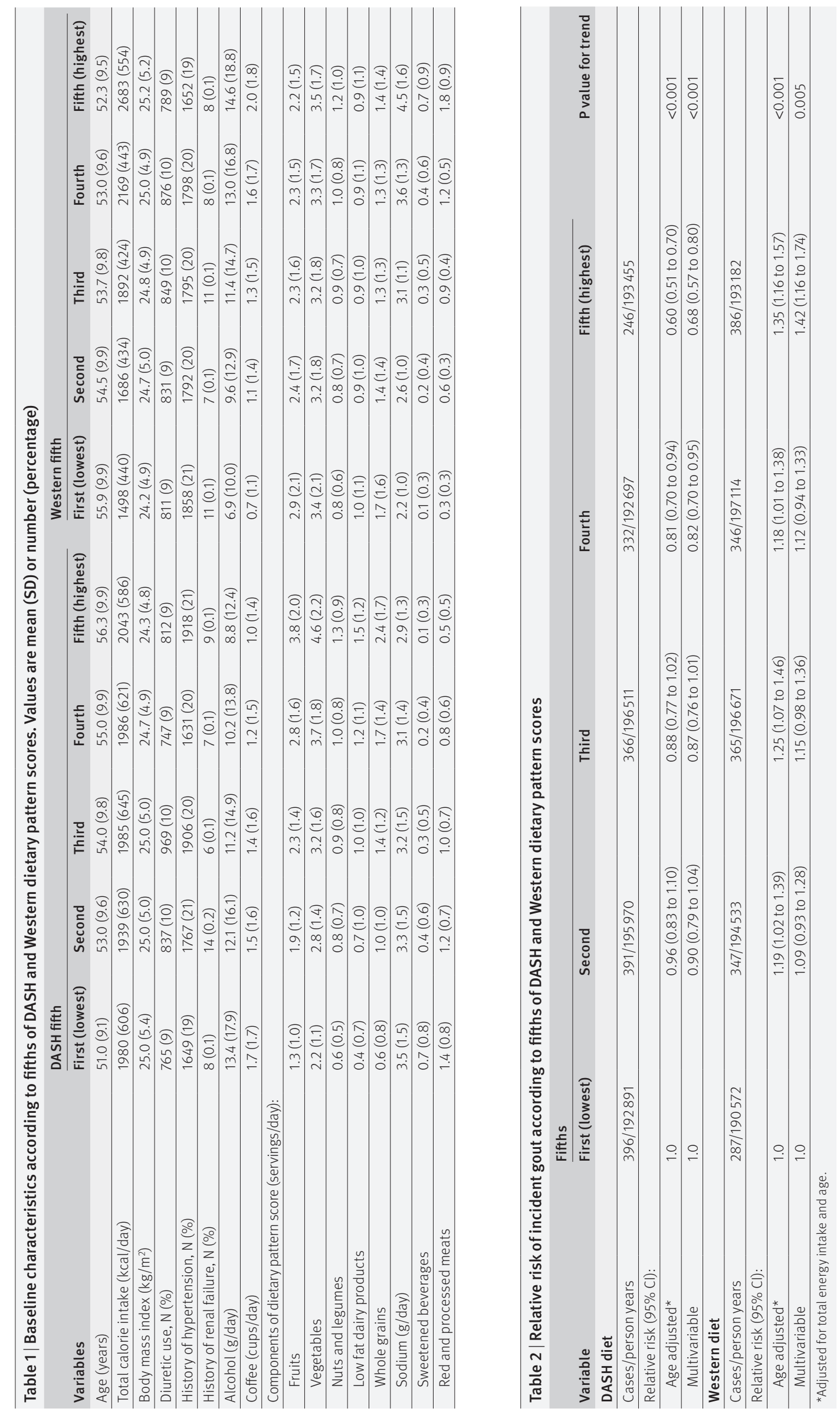

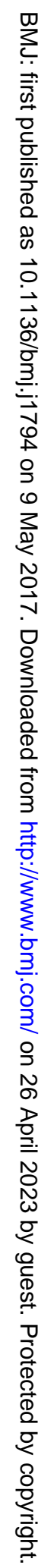




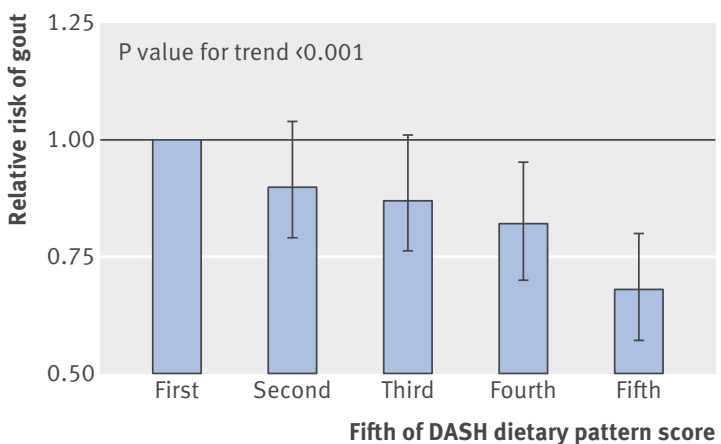

Fig 1 Multivariable relative risk of incident gout and $95 \%$ confidence interval according to fifth of DASH dietary pattern score

score was 1.42 (95\% confidence interval 1.16 to 1.74 , $\mathrm{P}$ value for trend 0.005$)$

Risk according to body mass index, alcohol use, and hypertension status

We conducted stratified analyses to evaluate whether the association between the DASH and Western dietary pattern scores and the risk of gout varied according to body mass index, alcohol use, and hypertension status. Table 3 shows that relative risks from these stratified analyses consistently suggested associations similar to those from the main analysis, and there was no significant interaction with these variables (all $\mathrm{P}$ values for interaction $>0.17$ ).

\section{Discussion}

In this large prospective cohort study, we found that the Dietary Approaches to Stop Hypertension (DASH) diet was associated with a lower risk of incident gout. In contrast, the Western diet was associated with an increased risk of incident gout. These associations were

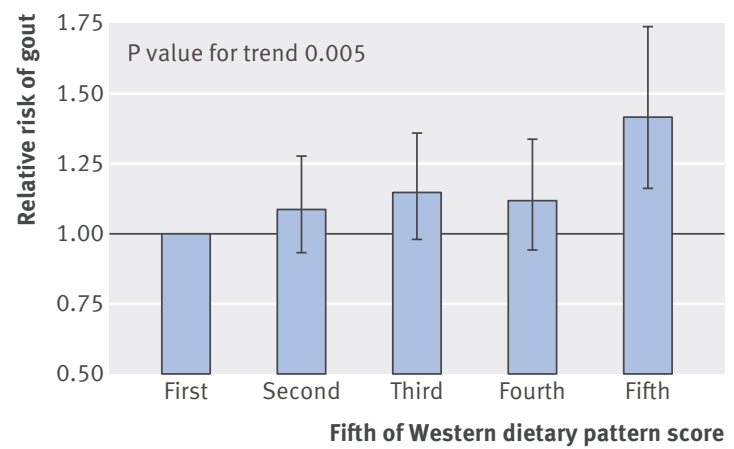

Fig 2 Multivariable relative risk of incident gout and $95 \%$ confidence interval according to fifth of Western dietary pattern score

independent of risk factors for gout such as age, body mass index, hypertension, renal failure, diuretic use, alcohol intake, and coffee intake, and did not differ by body mass index, alcohol intake, and hypertension status. These data suggest that the DASH diet could offer an attractive dietary strategy that would be useful in the prevention of gout and its comorbidities in high risk patients with hyperuricemia. If confirmed by future intervention trials, this approach would be particularly relevant to patients with gout who have hypertension and cardiovascular disease, given its antihypertensive and cardiovascular disease benefits.

The main components of the DASH diet include fruits, vegetables, nuts and legumes, low fat dairy products, and whole grains, combined with a low intake of sodium, sweetened beverages, and red and processed meats. This pattern substantially overlaps with previous study findings of individual dietary risk factors for hyperuricemia and gout such as meat, seafood, alcohol, fructose-rich beverages, as well as protective (or neutral) factors such as low fat dairy intake, vegetables,

\begin{tabular}{|c|c|c|c|c|c|c|c|}
\hline \multirow[b]{2}{*}{ Subgroup variable } & \multicolumn{5}{|c|}{ Multivariate relative risk $(95 \% \mathrm{Cl})$ per fifth } & \multicolumn{2}{|l|}{$P$ value } \\
\hline & First & Second & Third & Fourth & Fifth & For trend & For interaction \\
\hline \multicolumn{8}{|l|}{ DASH diet } \\
\hline \multicolumn{8}{|l|}{ Body mass index: } \\
\hline$<25$ & 1.0 & 0.90 (0.73 to 1.10$)$ & 0.81 (0.66 to 1.00$)$ & 0.76 (0.61 to 0.93$)$ & 0.62 (0.50 to 0.78$)$ & $<0.001$ & 0.72 \\
\hline$\geq 25$ & 1.0 & 0.91 (0.75 to 1.11) & 0.93 (0.76 to 1.13 ) & 0.88 (0.71 to 1.08$)$ & 0.74 (0.58 to 0.93 ) & 0.02 & \\
\hline \multicolumn{8}{|l|}{ Alcohol use: } \\
\hline Yes & 1.0 & $0.90(0.76$ to 1.07$)$ & $0.79(0.67$ to 0.95$)$ & 0.82 (0.68 to 0.97$)$ & 0.70 (0.57 to 0.85$)$ & $<0.001$ & 0.26 \\
\hline No & 1.0 & 1.05 (0.72 to 1.53$)$ & 1.33 (0.93 to 1.92$)$ & $1.06(0.72$ to 1.55$)$ & $0.69(0.45$ to 1.06$)$ & 0.15 & \\
\hline \multicolumn{8}{|l|}{ Hypertension: } \\
\hline Yes & 1.0 & 0.93 (0.77 to 1.11$)$ & $0.92(0.76$ to 1.11$)$ & $0.82(0.68$ to 1.00$)$ & 0.75 (0.61 to 0.93$)$ & 0.004 & 0.18 \\
\hline No & 1.0 & 0.88 (0.71 to 1.09$)$ & $0.81(0.64$ to 1.01$)$ & $0.82(0.65$ to 1.03$)$ & 0.57 (0.44 to 0.75$)$ & $<0.001$ & \\
\hline \multicolumn{8}{|l|}{ Western diet } \\
\hline \multicolumn{8}{|c|}{ Body mass index $\left(\mathrm{kg} / \mathrm{m}^{2}\right)$ : } \\
\hline$<25$ & 1.0 & $1.04(0.84$ to 1.29$)$ & $1.07(0.86$ to 1.34$)$ & $0.99(0.78$ to 1.27$)$ & $1.32(1.00$ to 1.73$)$ & 0.17 & 0.61 \\
\hline$\geq 25$ & 1.0 & 1.15 (0.91 to 1.47$)$ & 1.22 (0.95 to 1.55$)$ & 1.18 (0.91 to 1.53$)$ & 1.38 (1.03 to 1.86$)$ & 0.06 & \\
\hline \multicolumn{8}{|l|}{ Alcohol use: } \\
\hline Yes & 1.0 & 1.06 (0.87 to 1.28$)$ & 1.05 (0.86 to 1.28$)$ & 1.01 (0.82 to 1.24$)$ & 1.23 (0.97 to 1.57 ) & 0.25 & 0.62 \\
\hline No & 1.0 & 1.16 (0.80 to 1.68$)$ & $1.21(0.82$ to 1.78$)$ & $0.96(0.62$ to 1.49$)$ & 1.52 (0.93 to 2.48$)$ & 0.32 & \\
\hline \multicolumn{8}{|l|}{ Hypertension: } \\
\hline Yes & 1.0 & 1.10 (0.90 to 1.35$)$ & 1.13 (0.92 to 1.40$)$ & 1.06 (0.84 to 1.33 ) & 1.21 (0.94 to 1.58 ) & 0.30 & 0.34 \\
\hline No & 1.0 & 1.06 (0.82 to 1.37$)$ & 1.14 (0.88 to 1.47$)$ & 1.11 (0.84 to 1.47$)$ & 1.52 (1.12 to 2.07$)$ & 0.02 & \\
\hline
\end{tabular}


cherries, legumes, nuts, and plant protein..$^{13-25}$ This explains why the dietary pattern is associated with a lower risk of gout in a dose-responsive manner. Reduced purine loading and insulin resistance, as well as the resulting uricosuric effects, have been thought to be potential mechanisms behind anti-gout foods leading to lower serum uric acid levels. ${ }^{50-52}$ Indeed, a recent ancillary analysis $(n=103)$ of a DASH diet trial ${ }^{28}$ found that the DASH diet lowers serum uric acid levels compared with a typical American diet (ie, control diet), particularly among those with hyperuricemia (ie, by 1.0 $\mathrm{mg} / \mathrm{dL}$ in those with a baseline serum uric acid level $\geq 6$ $\mathrm{mg} / \mathrm{dL}$ and by $1.3 \mathrm{mg} / \mathrm{dL}$ in those with a baseline serum uric acid $\geq 7 \mathrm{mg} / \mathrm{dL}$ ). ${ }^{10}$ These findings collectively suggest that the DASH diet's ability to lower uric acid levels can be translated to a lower risk of developing gout.

The DASH diet has other important health benefits relevant to patients with hyperuricemia or gout, both of which are associated with a high level of cardiovascular metabolic comorbidities ${ }^{353}$ and mortality. ${ }^{6}$ A series of randomized controlled trials found that DASH based diets substantially reduce blood pressure. ${ }^{27-30}$ For example, the original DASH trial found that the DASH diet reduced systolic and diastolic blood pressure by 11.4 and $5.5 \mathrm{~mm} \mathrm{Hg}$ more than the control diet, respectively. ${ }^{27}$ As hypertension is present in $74 \%$ of patients with gout (and in 50\% of people with hyperuricemia), ${ }^{3}$ nearly three out of four patients with gout would already be indicated for the DASH diet to treat their hypertension. Our findings, together with the recently shown urate lowering effect of the DASH diet, ${ }^{10}$ suggest that the diet could also help their gout. To that end, the American Heart Association guidelines for cardiovascular health and the dietary management of hypertension endorse foods and dietary approaches that are similar to those included in the DASH diet. ${ }^{9}$ Furthermore, the DASH diet has been shown to be associated with a lower risk of coronary heart disease, stroke, and kidney stones, ${ }^{93738}$ all of which are correlates of gout and hyperuricemia. ${ }^{3}$ As such, the DASH diet could be useful not only in the prevention of gout and its comorbidities in high risk patients with hyperuricemia, but also when urate lowering drugs are not yet indicated in patients with gout (a more frequently encountered scenario in primary care). Moreover, even when such drugs are indicated, the DASH diet would serve as a useful adjunct therapy to improve the cardiovascular comorbidity profile of the patient. Finally, many patients with gout prefer non-pharmacologic options for treatment, according to a recent survey by the Gout and Uric Acid Education Society ${ }^{49}$. There is also some skepticism about the approach of treating gout with drugs to lower a patient's urate level ("treating to target") raised by the recent American College of Physicians gout guidelines for general physicians. Therefore, our results and further evidence about the efficacy of non-pharmacologic options have become more relevant to gout care. ${ }^{54}$

Our findings also have practical implications for the prevention of gout. While individual dietary risk factors for hyperuricemia and gout have been identified, a piecemeal approach to modifying the various, yet limited, number of specific dietary risk factors is often ineffective and impractical. For example, focusing exclusively on reducing protein content in the conventional diet low in purine often provides an incomplete dietary recommendation without considering the proper replacement with healthy calorie sources, which in turn could actually worsen the metabolic syndrome and its consequences, ${ }^{78}$ which include hyperuricemia and gout. In contrast, a healthful complete dietary pattern approach such as the DASH diet reflects the way foods are consumed in reality and can facilitate the dissemination and adoption (by providing comprehensive diet instructions and ongoing support) in both public health and clinical practice. Moreover, unlike the conventional low purine approach, another important advantage of the DASH diet is its palatability, ${ }^{55}$ which is important for sustainability. ${ }^{78}$ For example, a post hoc survey of a DASH trial found that participants enjoyed the DASH diet and were willing to continue with it more than the control diet. ${ }^{55}$

In contrast, we found that the Western diet was independently associated with an increased risk of gout. This provides the first prospective evidence that the Western diet, reflecting fast foods abundantly available in Western countries, can explain the increasing prevalence of gout observed in such settings. ${ }^{21112}$ Increased purine intake from animal sources and insulin resistance resulting in anti-uricosuric effects are likely mechanisms of this diet leading to hyperuricemia and eventually gout. ${ }^{50-}$ ${ }^{52}$ Replacing the Western diet with a healthful eating approach such as the DASH diet could help prevent the rising burden of gout, in addition to other expected public health benefits (eg, hypertension benefits).

\section{Strengths and weaknesses of this study}

Our study had a large number of confirmed cases of incident gout, and we prospectively collected and validated the dietary intake data. Potential biased recall of diet was avoided in this study because the intake data were collected before the diagnosis of gout. As dietary consumption was self reported by questionnaire, some misclassification of the exposure is inevitable. However, dietary consumption that was self reported has been extensively validated in subsamples of this cohort, ${ }^{33} 34$ and any remaining misclassification would have likely biased the results toward the null. The use of repeated dietary assessments in the analysis not only accounts for changes in dietary consumption over time, but also decreases measurement error. The validity of gout ascertainment in these cohorts ${ }^{13} 1635$ has been documented by the high degree of concordance with medical record review.

The cohort of male medical professionals minimizes the potential for confounding associated with socioeconomic status, and we were able to obtain high quality data with minimal loss to follow-up. Although the absolute rates of gout and the distribution of dietary intake may not be representative of a random sample of American men, the biological effects of the DASH diet on gout (as reflected by the relative risks) should be 
similar. Our findings can be extrapolated most directly to white men over the age of 40 with no history of gout. Since the prevalence of risk factors for gout and its incidence tend to be higher in the general population and among African-Americans, the magnitude of the absolute risk difference associated with the DASH and Western diets might be greater than that observed in the current study.

\section{Conclusion}

Our findings provide the first prospective evidence that the DASH diet is associated with a lower risk of incident gout, whereas the Western diet is associated with an increased risk of incident gout. The DASH diet could offer an attractive preventive dietary approach for the risk of gout. These data also provide support for intervention studies to examine the effects of the DASH diet on serum uric acid levels among patients with gout as well as for the risk of gout flares.

Contributors: SKR and HKC designed the study. HKC and GCC collected the data. SKR, NL, and HKC provided statistical expertise. SKR and NL analyzed the data. SKR wrote the first draft of the manuscript. All authors interpreted the results and approved the final version of the manuscript. SKR and HKC are the guarantors.

Funding: This research was supported by grants R01AR065944 and UM1CA1 67552 from the National Institutes of Health. The funder had no role in the design and conduct of the study; collection, management, analysis, and interpretation of the data; and preparation, review, or approval of the manuscript.

Competing interests: All authors have completed the ICMIE uniform disclosure form at www.icmje.org/coi_disclosure.pdf and declare: no support from any organization for the submitted work other than that described above; no financial relationships with any organizations that might have an interest in the submitted work in the previous three years. HKC reports grants from AstraZeneca, consulting fees from Takeda, and consulting fees from Selecta outside the submitted work.

Ethical approval: This study was approved by the institutional review board of the Harvard TH Chan School of Public Health.

Data sharing: No additional data available.

Transparency: The lead authors (SKR and HKC) affirm that the manuscript is an honest, accurate, and transparent account of the study being reported; that not important aspects of the study have been omitted; and that any discrepancies from the study as planned have been explained.

This is an Open Access article distributed in accordance with the Creative Commons Attribution Non Commercial (CC BY-NC 4.0) license, which permits others to distribute, remix, adapt, build upon this work non-commercially, and license their derivative works on different terms, provided the original work is properly cited and the use is non-commercial. See: http://creativecommons.org/licenses/ by-nc/4.0/

1 Kuo CF, Grainge MJ, Mallen C, et al. Rising burden of gout in the UK but continuing suboptimal management: a nationwide population study. Ann Rheum Dis 2015;74:661-7. doi:10.1136/ annrheumdis-2013-204463.

2 Zhu Y, Pandya BJ, Choi HK. Prevalence of gout and hyperuricemia in the US general population: the National Health and Nutrition Examination Survey 2007-2008. Arthritis Rheum 2011;63:3136-41. doi:10.1002/art.30520.

3 Zhu Y, Pandya BJ, Choi HK. Comorbidities of gout and hyperuricemia in the US general population: NHANES 2007-2008. Am J Med 2012;125:679-687.e1.

4 Choi HK, Ford ES, Li C, Curhan G. Prevalence of the metabolic syndrome in patients with gout: the Third National Health and Nutrition Examination Survey. Arthritis Rheum 2007:57:109-15. doi.101002/art 22466

5 Krishnan E, Baker JF, Furst DE, Schumacher HR. Gout and the risk of acute myocardial infarction. Arthritis Rheum 2006;54:2688-96. doi:10.1002/art.22014

6 Choi HK, Curhan G. Independent impact of gout on mortality and risk for coronary heart disease. Circulation 2007;116:894-900. doi:10.1161/CIRCULATIONAHA.107.703389.
7 Dessein PH, Shipton EA, Stanwix AE, Joffe BI, Ramokgadi J. Beneficial effects of weight loss associated with moderate calorie/carbohydrate restriction, and increased proportional intake of protein and unsaturated fat on serum urate and lipoprotein levels in gout: a pilot study. Ann Rheum Dis 2000;59:539-43. doi:10.1136/ard.59.7.539.

8 Fam AG. Gout, diet, and the insulin resistance syndrome. J Rheumatol 2002;29:1350-5

9 Sacks FM, Campos H. Dietary therapy in hypertension. N EnglJ Med 2010;362:2102-12. doi:10.1056/NEJMct0911013.

10 Juraschek SP, Gelber AC, Choi HK, Appel LJ, Miller ER 3rd. Effects of the Dietary Approaches to Stop Hypertension (DASH) Diet and Sodium Intake on Serum Uric Acid. Arthritis Rheumatol 2016;68:3002-9. doi:10.1002/art.39813.

11 Rai SK, Aviña-Zubieta JA, McCormick N, et al. The rising prevalence and incidence of gout in British Columbia, Canada: Population-based trends from 2000 to 2012. Semin Arthritis Rheum 2017:46:451-6doi:1 0.1016/j.semarthrit.2016.08.006.

12 Kuo CF, Grainge MJ, Zhang W, Doherty M. Global epidemiology of gout: prevalence, incidence and risk factors. Nat Rev Rheumatol 2015:11:649-62. doi:10.1038/nrrheum.2015.91.

13 Choi HK, Atkinson K, Karlson EW, Willett W, Curhan G. Purine-rich foods, dairy and protein intake, and the risk of gout in men. N Engl J Med 2004:350:1093-103 doi:10.1056/NEJMoa035700.

14 Choi HK, Liu S, Curhan G. Intake of purine-rich foods, protein, and dairy products and relationship to serum levels of uric acid: the Third National Health and Nutrition Examination Survey. Arthritis Rheum 2005;52:283-9. doi:10.1002/art.20761.

15 Zhang Y, Chen C, Choi H, et al. Purine-rich foods intake and recurrent gout attacks. Ann Rheum Dis 2012;71:1448-53. doi:10.1136/ annrheumdis-2011-201215.

16 Choi HK, Atkinson K, Karlson EW, Willett W, Curhan G. Alcohol intake and risk of incident gout in men: a prospective study. Lancet 2004:363:1277-81. doi:10.1016/S0140-6736(04)16000-5.

17 Choi HK, Curhan G. Beer, liquor, and wine consumption and serum uric acid level: the Third National Health and Nutrition Examination Survey. Arthritis Rheum 2004;51:1023-9. doi:10.1002/art.20821.

18 Gao X, Qi L, Qiao N, et al. Intake of added sugar and sugar-sweetened drink and serum uric acid concentration in US men and women. Hypertension 2007:50:306-12. doi:10.1161/ HYPERTENSIONAHA.107.091041.

19 Choi HK, Curhan G. Soft drinks, fructose consumption, and the risk of gout in men: prospective cohort study. BMJ 2008;336:309-12 doi:10.1136/bmj.39449.819271.BE.

20 Choi HK, Willett W, Curhan G. Fructose-rich beverages and risk of gou in women. JAMA 2010;304:2270-8. doi:10.1001/jama.2010.1638.

21 Nguyen S, Choi HK, Lustig RH, Hsu CY. Sugar-sweetened beverages, serum uric acid, and blood pressure in adolescents. J Pediatr 2009;154:807-13. doi:10.1016/j.jpeds.2009.01.015.

22 Gao X, Curhan G, Forman IP, Ascherio A, Choi HK. Vitamin C intake and serum uric acid concentration in men. J Rheumatol 2008;35:1853-8.

23 Choi HK, Gao X, Curhan G. Vitamin C intake and the risk of gout in men: a prospective study. Arch Intern Med 2009;169:502-7. doi:10.1001/archinternmed.2008.606

24 Huang HY, Appel LJ, Choi MJ, et al. The effects of vitamin C supplementation on serum concentrations of uric acid: results of a randomized controlled trial. Arthritis Rheum 2005;52:1843-7. doi:10.1002/art.21105.

25 Juraschek SP, Miller ER 3rd,, Gelber AC. Effect of oral vitamin C supplementation on serum uric acid: a meta-analysis of randomized controlled trials. Arthritis Care Res (Hoboken) 2011;63:1295-306 doi:10.1002/acr.20519.

26 van Dam RM, Rimm EB, Willett WC, Stampfer MJ, Hu FB. Dietary patterns and risk for type 2 diabetes mellitus in U.S. men. Ann Intern Med 2002;136:201-9. doi:10.7326/0003-4819-136-3-200202050-00008.

27 Appel LJ, Moore TJ, Obarzanek E, et al. DASH Collaborative Research Group. A clinical trial of the effects of dietary patterns on blood pressure. N Engl / Med 1997;336:1117-24. doi:10.1056/ NEJM199704173361601.

28 Sacks FM, Svetkey LP, Vollmer WM, et al. DASH-Sodium Collaborative Research Group. Effects on blood pressure of reduced dietary sodium and the Dietary Approaches to Stop Hypertension (DASH) diet. N Engl I Med 2001;344:3-10. doi:10.1056/NEJM200101043440101.

29 Appel LJ, Sacks FM, Carey VJ, et al. OmniHeart Collaborative Research Group. Effects of protein, monounsaturated fat, and carbohydrate intake on blood pressure and serum lipids: results of the OmniHeart randomized trial. JAMA 2005;294:2455-64. doi:10.1001/jama.294.19.2455.

30 Appel LJ, Champagne CM, Harsha DW, et al. Writing Group of the PREMIER Collaborative Research Group. Effects of comprehensive lifestyle modification on blood pressure control: main results of the PREMIER clinical trial. JAMA 2003;289:2083-93. doi:10.1001/ jama.289.16.2083.

31 Shai I, Schwarzfuchs D, Henkin Y, et al. Dietary Intervention Randomized Controlled Trial (DIRECT) Group. Weight loss with a low-carbohydrate, Mediterranean, or low-fat diet. N Engl I Med 2008;359:229-41. doi:10.1056/NEJMoa0708681. 
32 de Lorgeril M, Salen P, Martin JL, Monjaud I, Delaye J, Mamelle N. Mediterranean diet, traditional risk factors, and the rate of cardiovascular complications after myocardial infarction: final report of the Lyon Diet Heart Study. Circulation 1999;99:779-85. doi:10.1161/01.CIR.99.6.779.

33 Rimm EB, Giovannucci EL, Stampfer MJ, Colditz GA, Litin LB, Willett WC. Reproducibility and validity of an expanded self-administered semiquantitative food frequency questionnaire among male health professionals. Am J Epidemiol 1992;135:1114-26, discussion 1127-36. doi:10.1093/oxfordjournals.aje.a116211.

34 Willett WC, Sampson L, Stampfer MJ, et al. Reproducibility and validity of a semiquantitative food frequency questionnaire. Am J Epidemiol 1985;122:51-65. doi:10.1093/oxfordjournals.aje.a114086.

35 Choi HK, Atkinson K, Karlson EW, Curhan G. Obesity, weight change, hypertension, diuretic use, and risk of gout in men: the health professionals follow-up study. Arch Intern Med 2005;165:742-8. doi:10.1001/archinte.165.7.742.

36 Willett W. Nutritional Epidemiology.1st ed. Oxford University Press, 1990.

37 Fung TT, Chiuve SE, McCullough ML, Rexrode KM, Logroscino G, Hu FB. Adherence to a DASH-style diet and risk of coronary heart disease and stroke in women. Arch Intern Med 2008;168:713-20. doi:10.1001/ archinte.168.7.713

38 Taylor EN, Fung TT, Curhan GC. DASH-style diet associates with reduced risk for kidney stones. I Am Soc Nephrol 2009;20:2253-9. doi:10.1681/ASN.2009030276.

39 Karanja NM, Obarzanek E, Lin PH, et al. DASH Collaborative Research Group. Descriptive characteristics of the dietary patterns used in the Dietary Approaches to Stop Hypertension Trial. J Am Diet AssoC 1999;99(Suppl):S19-27. doi:10.1016/S0002-8223(99)00412-5.

40 Fung TT, Schulze M, Manson JE, Willett WC, Hu FB. Dietary patterns, meat intake, and the risk of type 2 diabetes in women. Arch Intern Med 2004;164:2235-40. doi:10.1001/archinte.164.20.2235.

41 Fung TT, Willett WC, Stampfer MJ, Manson JE, Hu FB. Dietary patterns and the risk of coronary heart disease in women. Arch Intern Med 2001;161:1857-62. doi:10.1001/archinte.161.15.1857.

42 Fung T, Hu FB, Fuchs C, et al. Major dietary patterns and the risk of colorectal cancer in women. Arch Intern Med 2003;163:309-14. doi:10.1001/archinte.163.3.309.
43 Hu FB, Rimm EB, Stampfer MJ, Ascherio A, Spiegelman D, Willett WC. Prospective study of major dietary patterns and risk of coronary heart disease in men. Am I Clin Nutr 2000;72:912-21.

44 Hu FB, Rimm E, Smith-Warner SA, et al. Reproducibility and validity of dietary patterns assessed with a food-frequency questionnaire. Am J Clin Nutr 1999;69:243-9.

45 Kim JO, Mueller CW. Factor Analysis: Statistical Methods and Practical Issues.Sage Publications, 1978doi:10.4135/9781412984256.

46 Wallace SL, Robinson H, Masi AT, Decker IL, McCarty DJ, Yü TF. Preliminary criteria for the classification of the acute arthritis of primary gout. Arthritis Rheum 1977;20:895-900. doi:10.1002/art.1780200320.

47 Hu FB, Stampfer MJ, Manson JE, et al. Dietary fat intake and the risk of coronary heart disease in women. N Engl I Med 1997:337:1491-9. doi:10.1056/NEIM199711203372102.

48 Hu FB, Stampfer MJ, Manson JE, et al. Dietary protein and risk of ischemic heart disease in women. Am / Clin Nutr 1999;70:221-7.

49 Singh JA, Shah N, Edwards NL. A cross-sectional internet-based patient survey of the management strategies for gout. BMC Complement Altern Med 2016;16:90. doi:10.1186/s12906-016-1067-3.

50 Ter Maaten IC, Voorburg A, Heine RI, Ter Wee PM, Donker AJ, Gans RO. Renal handling of urate and sodium during acute physiological hyperinsulinaemia in healthy subjects. Clin Sci (Lond) 1997;92:51-8. doi:10.1042/cs0920051

51 Muscelli E, Natali A, Bianchi S, et al. Effect of insulin on renal sodium and uric acid handling in essential hypertension. Am J Hypertens 1996;9:746-52. doi:10.1016/0895-7061(96)00098-2

52 Emmerson B. Hyperlipidaemia in hyperuricaemia and gout. Ann Rheum Dis 1998;57:509-10. doi:10.1136/ard.57.9.509.

53 Choi HK, Mount DB, Reginato AM. American College of Physicians American Physiological Society. Pathogenesis of gout. Ann Intern Med 2005:143:499-516. doi:10.7326/0003-4819-143-7-200510040-00009.

54 Qaseem A, Harris RP, Forciea MA. Clinical Guidelines Committee of the American College of Physicians. Management of Acute and Recurrent Gout: A Clinical Practice Guideline From the American College of Physicians. Ann Intern Med 2017;166:58-68. doi:10.7326/M16-0570.

55 Karanja N, Lancaster KJ, Vollmer WM, et al. Acceptability of sodium-reduced research diets, including the Dietary Approaches To Stop Hypertension diet, among adults with prehypertension and stage 1 hypertension. J Am Diet Assoc 2007;107:1530-8. doi:10.1016/i.jada.2007.06.013. 